Measurement of the Auger Parameter and Wagner Plot for Uranium Compounds

K. S. Holliday, W. Siekhaus, A. J. Nelson

October 12, 2012

Journal of Vacuum Science and Technology A 
This document was prepared as an account of work sponsored by an agency of the United States government. Neither the United States government nor Lawrence Livermore National Security, LLC, nor any of their employees makes any warranty, expressed or implied, or assumes any legal liability or responsibility for the accuracy, completeness, or usefulness of any information, apparatus, product, or process disclosed, or represents that its use would not infringe privately owned rights. Reference herein to any specific commercial product, process, or service by trade name, trademark, manufacturer, or otherwise does not necessarily constitute or imply its endorsement, recommendation, or favoring by the United States government or Lawrence Livermore National Security, LLC. The views and opinions of authors expressed herein do not necessarily state or reflect those of the United States government or Lawrence Livermore National Security, LLC, and shall not be used for advertising or product endorsement purposes. 


\title{
Measurement of the Auger Parameter and Wagner Plot for
}

\section{Uranium Compounds}

\begin{abstract}
K. S. Holliday, W. Siekhaus, A. J. Nelson
Lawrence Livermore National Laboratory, 7000 East Avenue, Livermore CA 94551 USA

In this study the photoemission from the $\mathrm{U}_{4} \mathrm{f}_{7 / 2}$ and $4 \mathrm{~d}_{5 / 2}$ states and the $\mathrm{U} \mathrm{N}_{6} \mathrm{O}_{45} \mathrm{O}_{45}$ and $\mathrm{N}_{67} \mathrm{O}_{45} \mathrm{~V}$ X-ray excited Auger transitions were measured for a range of uranium compounds. The data are presented in Wagner plots and the Auger parameter is calculated to determine the utility of this technique in the analysis of uranium materials. It was demonstrated that the equal core level shift assumption holds for uranium. It was therefore possible to quantify the relative relaxation energies, and uranium was found to have localized core hole shielding. The position of compounds within the Wagner plot made it possible to infer information on bonding character and local electron density. It was also shown that the oxides have similar initial state effects regardless of oxidation state.
\end{abstract}

\section{INTRODUCTION}

X-ray photoemission spectroscopy (XPS) has long been used to provide information on oxidation state, chemical environment, and bonding characteristics of uranium surfaces. ${ }^{1}$ The binding energy of the $U$ 4f electrons depends on both oxidation state and local environment, which makes unambiguous interpretation of oxidation state based on XPS peak position impossible. This is illustrated in recent work showing that even after peak deconvolution, the pentavalent uranium in uraninite has the same binding energy as the hexavalent uranium in brannerite. ${ }^{2}$ Another complication is that mixed valence uranium compounds have been shown to have a smaller separation in binding energies than that of pure $\mathrm{UO}_{2}$ and $\mathrm{UO}_{3} .{ }^{3}$ One solution that has found success in uranium oxides is examining the satellite features that are caused by the photoelectron promoting a valence electron into the conduction band or continuum. ${ }^{2,4,5}$ This results in the detection of a photoelectron with slightly less kinetic energy than the parent peak. 
1 Some of these satellite peaks, such as the satellite $8 \mathrm{eV}$ from the parent peak of pentavalent

2 uranium, have been hypothesized to be exclusively due to charge transfer from the oxygen $2 p$

3 ligand band. ${ }^{4}$ Because the satellite phenomenon does not arise from the atomic character of the

4 uranium, it is unlikely that this technique will be able to be universally applied to a diverse

5 sampling of uranium compounds. There is a need for analyzing samples such as intermetallics,

6 used for armor or in advanced nuclear fuel, and uranium tetrafluoride which is used as a starting

7 material for the uranium hexafluoride needed in the isotope enrichment process. ${ }^{6}$

Additional information available in the XPS spectra are the peaks arising from the Auger

9 electron process. The X-ray excited Auger electron peak when combined with the core-level data

10 has been shown to be a powerful tool for gaining information on oxidation state, bonding

11 character, and the local environment in other elements. ${ }^{7-9}$ The Auger parameter is defined as the

12 sum of the photoelectron binding energy and the Auger electron kinetic energy. As such, the

13 combination is independent of shifts due to charging and calibration. This makes the Auger

14 parameter a reliable value even when measuring insulators without a reliable calibration source. ${ }^{7}$

15 This is of particular importance with unknown uranium compounds that can contain carbon as

16 carbide, making the typical calibration to the $\mathrm{C} 1 \mathrm{~s}$ peak incorrect. ${ }^{10}$ The Auger parameter, while

17 useful, is only a one dimensional value. More information can be obtained if the Auger electron

18 kinetic energy and core-level binding energy is plotted in a two-dimensional figure. This two

19 dimension plot known as a Wagner plot has the Auger electron kinetic energy on the ordinate

20 and the core-level binding energy on the abscissa in the negative direction. ${ }^{7}$ The relative position

21 of each compound gives information on the core hole shielding provided by the ligand

22 environment and the relative covalency of the bonding. ${ }^{7-9}$ Also, because the X-ray excited Auger 
1 transition is a two electron process, it can often result in larger energy shifts as compared to the

2 photoemission process due to enhanced relaxation.

The Wagner plot makes it possible to distinguish between initial and final state effects. ${ }^{7-9}$

4 The initial state is defined as the process which creates the core hole, while the final state is the

5 relaxation of the electron orbitals in response to the newly created core hole. In the initial state,

6 the binding energy of a photoelectron is dependent on three factors: the nature of that orbital as

7 defined by Koopmans' theorem, the atomic contribution to core electron binding energy, and the

8 contribution from the surrounding atoms referred to as the Madelung potential, site potential, or

9 electrostatic self-potential. The nature of the orbital can be calculated by Hartree-Fock and

10 because we are examining a single element, uranium, this can be taken as a constant, $\mathrm{C}$. The

11 atomic contribution is dependent on the valence charge, $\mathrm{q}$, and the change in core potential

12 resulting from the removal of a valence electron, $\mathrm{k}$. Lastly, the site potential, $\mathrm{V}$, is the

13 contribution from surrounding atoms and can be thought of as the sum of net charges at defined

14 distances from the core ionized atom. Therefore, the photoelectron binding energy in the initial

15 state, $\mathrm{E}_{\mathrm{b}}(\mathrm{i})$, can be defined by equation 1.

$$
\mathrm{E}_{\mathrm{b}}(\mathrm{i})=\mathrm{C}+\mathrm{kq}+\mathrm{V}
$$

17 In the final state of the photoemission process, the electronic states relax around the core

18 hole, which imparts additional energy to the photoelectron, changing the binding energy that is

19 detected. This relaxation energy comes from both the atomic relaxation, $\mathrm{R}^{\mathrm{a}}$, and from

20 contributions from surrounding atoms, $\mathrm{R}^{\mathrm{ea}}$. This atomic and extra-atomic relaxation therefore

21 adds energy to the detected electron, which can be related to the core electron binding energy,

$22 \quad \mathrm{E}_{\mathrm{b}}(\mathrm{C})$, by equation 2 .

$$
\mathrm{E}_{\mathrm{b}}(\mathrm{C})=\mathrm{C}+\mathrm{kq}+\mathrm{V}-\mathrm{R}^{\mathrm{a}}-\mathrm{R}^{\mathrm{ea}}
$$


1 The extra-atomic relaxation can occur by electron transfer to localized states in which the

2 bonding character is of little relevance, or the electron can be transferred to a bonding orbital in

3 which the degree of shielding that occurs is highly dependent on the character of the bonding

4 orbital. A similar explanation of initial and final state can be applied to the Auger process, where

5 the creation of the two-hole state is defined as initial and the relaxation of that state is final. It has

6 been shown that the photoemission process, including the relaxation of the initial core hole, can

7 be decoupled from the Auger process as described in the so-called two-step model. This two-step

8 model combined with Eqn. 2 allows one to relate the Auger electron kinetic energy, $\mathrm{E}_{\mathrm{k}}$, to the

9 binding energy, $\mathrm{E}_{\mathrm{b}}$, as detected by XPS.

$$
\mathrm{E}_{\mathrm{k}}=[\mathrm{C}+2(\mathrm{~V}+\mathrm{kq})]-3 \mathrm{E}_{\mathrm{b}}
$$

11 Eqn. 3 illustrates that compounds with similar initial state effects (i.e. $\mathrm{V}+\mathrm{kq}=$ constant) will

12 have a linear relationship with slope of -3 in a Wagner plot $\left(E_{k}\right.$ vs. $\left.-E_{b}\right)$. By combining the

13 information of the photoemission and Auger processes one can often obtain more information

14 than is available through either process alone.

In this study the $\mathrm{X}$-ray excited Auger electron from the $\mathrm{N}_{67} \mathrm{O}_{45} \mathrm{~V}$ and $\mathrm{N}_{6} \mathrm{O}_{45} \mathrm{O}_{45}$

16 transitions, combined with the binding energy of the $4 f_{7 / 2}$ and $4 d_{5 / 2}$ electrons, is measured in a

17 range of uranium compounds by XPS. These results are combined in Wagner plots and the

18 Auger parameter is calculated in order to determine the utility of this technique in the analysis of 19 uranium containing compounds.

\section{EXPERIMENT}

$22 \mathrm{~K} \alpha \mathrm{X}$-ray source $(1486.6 \mathrm{eV})$ for excitation and a spherical section analyzer with 16-element

23 multichannel detection system. The X-ray beam is incident normal to the sample and the detector 
1 is $45^{\circ}$ from normal. Spectra were collected with pass energy of $23.5 \mathrm{eV}$, giving an energy

2 resolution of $0.3 \mathrm{eV}$ that when combined with the $0.85 \mathrm{eV}$ full width half maximum (FWHM) $\mathrm{Al}$

$3 \mathrm{~K} \alpha$ line width gives a resolvable XPS peak width of $1.2 \mathrm{eV}$. Deconvolution of non-resolved

4 peaks was accomplished using Multipak 9.2 (PHI) curve fitting routines with asymmetric or

5 Gaussian-Lorentzian line-shapes and a Shirley background. The collected data were referenced

6 to an energy scale with binding energies for $\mathrm{Cu} 2 \mathrm{p}_{3 / 2}$ at $932.72+/-0.05 \mathrm{eV}$ and $\mathrm{Au} 4 \mathrm{f}_{7 / 2}$ at 84.01

$7+/-0.05 \mathrm{eV}$. Binding energies were also referenced to the $\mathrm{C} 1 \mathrm{~s}$ photoelectron line arising from

8 adventitious carbon at $284.6 \mathrm{eV} .{ }^{10}$ Low energy electrons and ions were used for specimen

9 neutralization. The Auger peak position was determined by the minimum of the first derivative,

10 performed within the MultiPak software, as is the common practice in Auger spectroscopy. ${ }^{11}$

11 Eqn. 4 is used to determine the kinetic energy of the Auger electron (KE) with a work function

$12\left(\Phi_{\mathrm{s}}\right)$ of $3.9 \mathrm{eV}$, the X-ray excitation energy (hv), and the binding energy (BE) which is

13 determined from the peak position in the XPS spectrum. The surface of the sample was polished

14 using $\mathrm{SiC}$ and diamond lapping films and/or sputtered with $3 \mathrm{kV} \mathrm{Ar}^{+}$ions. Sample history,

15 characterization and surface treatments are summarized below.

$$
\mathrm{KE}=\mathrm{h} v-\mathrm{BE}-\Phi_{\mathrm{s}}
$$

Two samples of uranium metal were analyzed in this study. One is pure uranium while

18 the other was treated by ion implantation of $\mathrm{C}^{+}$, which has been found to minimize surface

19 oxidation. ${ }^{12,13}$ Details on both samples are reported by Nelson et al. ${ }^{14}$ Oxidation at the surface

20 was removed by mechanical polishing followed by $\mathrm{Ar}^{+}$sputtering. The samples gave identical

21 results with the exception of greater oxide contamination of pure uranium due to fast oxidation

22 kinetics. 
It is well documented that a thin layer of $\mathrm{U}_{4} \mathrm{O}_{9} / \mathrm{U}_{3} \mathrm{O}_{7}$ will grow on $\mathrm{UO}_{2}$ when exposed to

2 air at ambient conditions. ${ }^{15,16}$ A single crystal of $\mathrm{UO}_{2}$ that has been exposed to the laboratory environment for greater than 25 years was examined by XPS without any surface treatment as an

4 example of tetra/penta-valent mixed uranium oxide. ${ }^{17}$ The sample was then mechanically

5 polished and sputtered to expose the underlying $\mathrm{UO}_{2}$ single crystal for analysis. Both the

$6 \mathrm{U}_{4} \mathrm{O}_{9} / \mathrm{U}_{3} \mathrm{O}_{7}$ layer and underlying $\mathrm{UO}_{2}$ crystal have been characterized in detail. ${ }^{18-20}$

A sample of amorphous $\mathrm{UO}_{3}$ was prepared by precipitation of uranium oxy-hydroxide

8 from uranyl acetate solution with base and calcined at $450^{\circ} \mathrm{C}$ in air to form the oxide. This was

9 confirmed to be $\mathrm{UO}_{3}$ through subsequent XPS analysis. The sample was then heated to $750^{\circ} \mathrm{C}$ in

10 air to form $\mathrm{U}_{3} \mathrm{O}_{8}$, an example of the penta/hexa-valent mixed uranium oxide. ${ }^{17}$ No surface

11 treatment was necessary for the analysis of $\mathrm{UO}_{3}$ and $\mathrm{U}_{3} \mathrm{O}_{8}$. The methodology used for the

12 preparation of $\mathrm{UO}_{3}$ and $\mathrm{U}_{3} \mathrm{O}_{8}$ can be found in the review of Grenthe et al. ${ }^{6}$

A single crystal of $\mathrm{UF}_{4}$ was synthesized by reacting $\mathrm{UO}_{2}$ with $\mathrm{HF}$ at elevated

14 temperatures in the Y-12 plant in Oak Ridge, Tennessee. ${ }^{21}$ It was determined that $\mathrm{Ar}^{+}$sputtering

15 with as little as $0.5 \mathrm{kV}$ acceleration preferentially removed fluorine from the surface,

16 significantly altering the surface composition. Therefore, the sample was mechanically polished

17 to remove minor surface contamination that had occurred during laboratory storage. XPS

18 analysis confirms that the sample is uranium tetrafluoride.

Lastly, an intermetallic sample, $\mathrm{URu}_{2} \mathrm{Si}_{2}$, was analyzed. It has gained considerable

20 interest in the last 20 years as a heavy fermion compound and has unusual electronic and

21 magnetic behavior at low temperatures. ${ }^{22-24}$ A single crystal of $\mathrm{URu}_{2} \mathrm{Si}_{2}$ was grown using the

22 Czochralski method and then annealed at $900^{\circ} \mathrm{C}$ for 7 days. The synthesis and characterization of

23 this sample can be found in previous publications. ${ }^{25,26}$ 


\section{RESULTS AND DISCUSSION}

The $\mathrm{U} 4 \mathrm{f}_{7 / 2,5 / 2}$ spin-orbit pair are adequate in characterizing known mono-valent uranium species as can be seen in Fig. 1. The signal to noise is lower in $\mathrm{URu}_{2} \mathrm{Si}_{2}$ because of the shorter analysis time used to minimize the signal from oxide ingrowth. The peak positions for each species are sufficiently separated to allow identification. Additionally, the peak shape yields information about the electronic structure. Specifically, the asymmetry of the $\mathrm{U}$ 4f peak in metallic $\mathrm{U}$ and intermetallic $\mathrm{URu}_{2} \mathrm{Si}_{2}$ is due to the manifold of states near the Fermi level. In $\mathrm{UO}_{2}$, there is a satellite peak at $\sim 6.5 \mathrm{eV}$ higher binding energy from the parent peak, which is due to the promotion of an oxygen $2 p$ electron that has bonding character with the $U$ $5 f$ state. ${ }^{4}$ Because $\mathrm{UO}_{3}$ has no electrons occupying the $5 \mathrm{f}$ state this is not possible, and the satellite is not observed. In $\mathrm{UF}_{4}$, the $\mathrm{U}_{4} \mathrm{f}_{7 / 2}$ peak is shifted to higher binding energy (382.6 eV). It has a satellite feature similar to the other tetravalent uranium sample $\left(\mathrm{UO}_{2}\right)$, in this case arising from the promotion of the fluorine $2 p$ electron. Because the fluorine $2 p$ state is at a higher binding energy than the oxygen $2 \mathrm{p}$, there is a greater separation $(7.5 \mathrm{eV})$ between the main peak and satellite feature of $\mathrm{UF}_{4}$ as compared to $\mathrm{UO}_{2}$. The relative positions of the oxygen and fluorine $2 \mathrm{p}$ bands can be seen in the valence band spectra shown in Fig. 2. The manifold at the Fermi level of the metal and intermetallic samples as well as the absence of an occupied $5 \mathrm{f}$ state in $\mathrm{UO}_{3}$ are also apparent in Fig. 2. The relative position of the $\mathrm{U} 4 \mathrm{f}$ peaks for $\mathrm{UF}_{4}, \mathrm{UO}_{2}$, and $\mathrm{UO}_{3}$ [Fig. 1] illustrate the difficulty in identifying uranium based compounds based on peak position alone. The $\mathrm{U}_{7 / 2}$ binding energies for tetravalent uranium species span from $\mathrm{UO}_{2}$ at $380.0 \mathrm{eV}$ to $\mathrm{UF}_{4}$ at $382.6 \mathrm{eV}$, while the hexavalent uranium as $\mathrm{UO}_{3}$ appears within this range at $380.8 \mathrm{eV}$. Additionally, the separation between tetravalent and hexavalent uranium oxides is only $0.8 \mathrm{eV}$, 
1 which makes unambiguous determination of mixed oxidation states impossible by peak position

2 alone.

To gain additional information on the sample, the region at high binding energy (low

4 kinetic energy) was collected to record the Auger transitions of uranium. The X-ray excited

$5 \quad \mathrm{~N}_{6} \mathrm{O}_{45} \mathrm{O}_{45}$ and $\mathrm{N}_{67} \mathrm{O}_{45} \mathrm{~V}$ Auger transitions for uranium metal are shown in Fig. 3. These peaks are

6 less intense than the photoemission peaks and appear in a region with increasing background.

7 Nevertheless, it is apparent that the onset peak position can be accurately determined by the

8 minimum of the first derivative, as is commonly used for Auger spectroscopy. The $\mathrm{N}_{67} \mathrm{O}_{45} \mathrm{~V}$

9 transition appears near a binding energy of $1200 \mathrm{eV}$, while the $\mathrm{N}_{6} \mathrm{O}_{45} \mathrm{O}_{45}$ transition is a doublet

10 that is near a binding energy of $1300 \mathrm{eV}$. The precise peak position was then used to calculate

11 the Auger electron kinetic energy according to Eqn. 4. The lowest binding energy peak of the

$12 \mathrm{~N}_{6} \mathrm{O}_{45} \mathrm{O}_{45}$ transition was used as the peak position, because it was the most intense. The binding

13 energies of the $U 4 f_{7 / 2}$ and $4 d_{5 / 2}$ peaks along with the kinetic energy of the Auger electrons from

14 the $\mathrm{N}_{67} \mathrm{O}_{45} \mathrm{~V}$ and $\mathrm{N}_{6} \mathrm{O}_{45} \mathrm{O}_{45}$ transitions can be found in Table 1.

The $\mathrm{U} 4 \mathrm{f}_{7 / 2}$ peak is the most intense and sharpest peak for uranium compounds and is

16 therefore the most commonly used in uranium characterization. Because of the high background

17 in detecting low kinetic energy electrons by XPS and the maximum excitation energy of Al Ka

$18 \mathrm{X}$-rays, the effective range for detecting Auger electrons is $100-1000 \mathrm{eV}$ kinetic energy based

19 on a $\mathrm{U} 4 \mathrm{f}$ initial core-hole. Within this range the $\mathrm{N}_{6} \mathrm{O}_{45} \mathrm{O}_{45}$ is the most intense Auger transition

20 that does not involve a valence band electron. ${ }^{10,11}$ Figure 4 presents the Wagner plot of the $\mathrm{U}$

$214 \mathrm{f}_{7 / 2}$ photoemission and $\mathrm{N}_{6} \mathrm{O}_{45} \mathrm{O}_{45}$ Auger transition. As can be seen in Fig. 4, all uranium

22 compounds, with the exception of $\mathrm{UF}_{4}$, have an Auger parameter of $\sim 564 \mathrm{eV}$. The consistency of

23 the Auger parameter in uranium compounds across various oxidation states and ligand 
environments indicates localized shielding. The Auger parameter of $\mathrm{UF}_{4}$ is significantly lower at $562 \mathrm{eV}$. The difference in $\mathrm{UF}_{4}$ is attributed to the extremely low polarizability of the fluorine atom, which is also seen in the electronegativity $\left(\mathrm{X}_{\mathrm{F}}=3.98, \mathrm{X}_{\mathrm{O}}=3.44\right) .{ }^{8}$ Because of this, the fluorine atom contributes very little electron density to shield the $\mathrm{U} 4 \mathrm{f}$ core hole resulting in a lower relaxation energy. This manifests in the Wagner plot as a lower Auger parameter because an increase in relaxation energy would increase the Auger electron kinetic energy. It is apparent in the Wagner plot that for nearly all uranium compounds the shift in the $\mathrm{N}_{6} \mathrm{O}_{45} \mathrm{O}_{45}$ Auger line is equal to the shift in the $4 \mathrm{f}_{7 / 2}$ photoemission line and little is gained in identification of an unknown. Nevertheless, a difference in Auger parameter could be an indication of a change in chemistry such as was the case in $\mathrm{UF}_{4}$.

The $\mathrm{N}_{67} \mathrm{O}_{45} \mathrm{~V}$ Auger transition is more intense than the $\mathrm{N}_{6} \mathrm{O}_{45} \mathrm{O}_{45}$ Auger transition and is greater influenced by the surrounding atoms, because it involves the valence band directly. The Wagner plot of the $\mathrm{N}_{67} \mathrm{O}_{45} \mathrm{~V}$ Auger transition and $4 \mathrm{f}_{7 / 2}$ photoemission is presented in Fig. 5. The overall positions of compounds remain the same as the Wagner plot with the $\mathrm{N}_{6} \mathrm{O}_{45} \mathrm{O}_{45}$ transition [Fig.4]. The uranium metal is still in the upper right, and the fluoride in the bottom left. The oxides remain clustered in the middle. There are however, some shifts that are significantly different due to the participation of valence electrons in the Auger process. The oxides have a larger shift in the Auger kinetic energy than in the photoemission process [Fig. 5]. This spreads the oxides in the vertical direction of the plot and they no longer appear with a consistent Auger parameter. The difference between the $\mathrm{UO}_{2}$ and $\mathrm{UO}_{3}$ Auger parameter is nearly $1 \mathrm{eV}$. Because the Auger parameter is independent of charging and calibration concerns, this small shift may be useful in determining unknown oxidation states. The oxides also group along a line with slope of -3 , which appears as +3 because of the negative orientation of the $x$-axis. As discussed earlier, 
1 this is an indication of similar initial state effects, where the sum of the site potential and

2 effective charge is a constant. O'Keeffe discusses this concept at depth, and has shown through

3 calculations that site potential scales with effective charge. ${ }^{27}$ This behavior has also been

$4 \quad$ observed experimentally for aluminum in zeolites. ${ }^{7}$ In the case of zeolites, aluminum is also

5 directly coordinated to oxygen. It was found that zeolite compounds along the line with slope of

$6-3$ were grouped according to coordination number. This trend is not found in uranium oxides,

7 but instead uranium oxides seem to transition smoothly by oxidation state.

8 In relation to the oxides, the metal and intermetallic $\mathrm{URu}_{2} \mathrm{Si}_{2}$ appear at lower Auger

9 kinetic energy in the case of the $\mathrm{N}_{67} \mathrm{O}_{45} \mathrm{~V}$ transition [Fig. 5] as compared to the $\mathrm{N}_{6} \mathrm{O}_{45} \mathrm{O}_{45}$

10 transition [Fig. 4]. This can be explained by noting the binding energy of the emitted Auger

11 electron in each case. For the $\mathrm{N}_{6} \mathrm{O}_{45} \mathrm{O}_{45}$ Auger transition the electron is emitted from a core level

12 that is localized at the $\mathrm{U}$ atom. Because of this, it has a relaxation in response to the two-core-

13 hole state that imparts greater energy to the emitted electron. For the $\mathrm{N}_{67} \mathrm{O}_{45} \mathrm{~V}$ Auger transition

14 the electron is emitted from the valence band, which in the case of the metal and intermetallic is

15 delocalized. Because this state is delocalized, it has lower relaxation energy in response to the

16 two-core-hole state than would be the case for a localized valence band, such as in the case of the

17 oxides. This results in the metallic and intermetallic appearing lower on the y-axis of the Wagner

18 plot using the $\mathrm{N}_{67} \mathrm{O}_{45} \mathrm{~V}$ [Fig. 5] as compared to the $\mathrm{N}_{6} \mathrm{O}_{45} \mathrm{O}_{45}$ [Fig. 4] Auger transition.

The $\mathrm{U}_{4} \mathrm{f}_{7 / 2}$ peak for the intermetallic $\mathrm{URu}_{2} \mathrm{Si}_{2}$ appears at a higher binding energy than

20 uranium metal, but does not have as high a binding energy as the $\mathrm{U}_{7 / 2}$ state in uranium

21 compounds which have a formal positive charge. This would suggest, while uranium in $\mathrm{URu}_{2} \mathrm{Si}_{2}$

22 does not have a formal positive charge, it has less electron density than uranium in the pure

23 metal. This might be expected from the higher electronegativity of $\mathrm{Si}(1.8)$ and $\mathrm{Ru}(2.2)$ as 
1 compared to uranium (1.7). This is also consistent with electron energy-loss spectroscopy of

$2 \mathrm{URu}_{2} \mathrm{Si}_{2}$ in which the $\mathrm{U} 5 \mathrm{f}$ electron occupancy was found to be between 2.6 and 2.8 , whereas

3 uranium metal has a 5 f occupancy of $3 .{ }^{25}$ The $\mathrm{UF}_{4}$ sample does not show any significant

4 difference in the Wagner plot of the $\mathrm{N}_{6} \mathrm{O}_{45} \mathrm{O}_{45}$ [Fig. 4] as compared to $\mathrm{N}_{67} \mathrm{O}_{45} \mathrm{~V}$ Auger transition

$5 \quad$ [Fig. 5].

6 The relative relaxation energies can be determined more quantitatively if one assumes an

7 equal core level shift in uranium. This is to say that different core levels are influenced in the

8 same way because they are a localized atomic orbital. Exceptions to this assumption involve

9 known cases of spatially extended core level electrons such as the $2 p$ of sulfur and phosphorous. ${ }^{7}$

10 In order to test this assumption in uranium, the $U \mathrm{Ud}_{5 / 2}$ photoemission peak was recorded and

11 plotted with the $\mathrm{N}_{67} \mathrm{O}_{45} \mathrm{~V}$ Auger transition in the Wagner plot of Fig. 6. The $\mathrm{U}_{4} \mathrm{~d}_{5 / 2}$

12 photoemission is broader and weaker than the $\mathrm{U}_{4} \mathrm{f}_{7 / 2}$. However, the Wagner plot has the same

13 results from both core levels showing that the equal core level shift assumption holds for

14 uranium. This can also be illustrated by plotting the Auger parameter determined with the $U 4 \mathrm{f}_{7 / 2}$

15 vs. $U 4 d_{5 / 2}$ photoemission [Fig. 7]. This scatter plot has a linear fit with slope of 1 and $r^{2}$ of 0.9 ,

16 confirming that the $U \mathrm{Uf}_{7 / 2}$ and $U 4 \mathrm{~d}_{5 / 2}$ produce the same core level shifts. Because of this, the

17 difference in Auger parameter $(\alpha)$ can be quantified as twice the difference in relaxation energy

$18\left(\mathrm{R}^{\mathrm{ea}}\right)$.

$$
\Delta \alpha=2 \Delta \mathrm{R}^{\mathrm{ea}}
$$

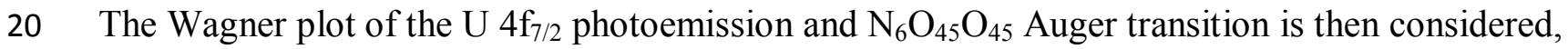

21 because it does not directly probe the valence band [Fig 4]. In this case it is obvious that the

22 metal, intermetallic, and oxides all exhibit similar relaxation energies. The Auger parameter of 
$1 \mathrm{UF}_{4}$ is approximately $2 \mathrm{eV}$ lower and therefore has $1 \mathrm{eV}$ lower relaxation energy due to the lack

2 of polarizability in fluorine as discussed above.

3 IV. CONCLUSIONS

$4 \quad$ The use of the Auger parameter and Wagner plot proved to be a useful tool in analyzing a 5 wide variety of uranium compounds. Combining the $4 \mathrm{f}_{7 / 2}$ photoemission peak with the $\mathrm{N}_{6} \mathrm{O}_{45} \mathrm{O}_{45}$

6 Auger transition resulted in a consistent Auger parameter for metal, intermetallic, and oxides,

7 which indicates localized shielding of the core hole and equivalent relaxation energy. $\mathrm{UF}_{4}$ was

8 found to have $1 \mathrm{eV}$ lower relaxation energy due to the extremely low polarizability of the

9 fluorine ligand. This quantification was possible by demonstrating that the equal core level shift

10 assumption holds for uranium. The $\mathrm{N}_{67} \mathrm{O}_{45} \mathrm{~V}$ Auger transition was able to give more insight into

11 the nature of the uranium bonding. In this Auger transition the metal relaxation energy was lower

12 because the delocalized valence band was less affected by the core hole than the localized

13 valence electrons of the oxides. The oxides have shown a greater shift in the $\mathrm{N}_{67} \mathrm{O}_{45} \mathrm{~V}$ as

14 compared to $\mathrm{N}_{6} \mathrm{O}_{45} \mathrm{O}_{45}$ Auger transition. In the Wagner plot with the $\mathrm{N}_{67} \mathrm{O}_{45} \mathrm{~V}$ Auger transition

15 and $\mathrm{U} 4 \mathrm{f}_{7 / 2}$ photoemission all of the oxide samples fall on a line with slope of -3 . This indicates

16 similar initial state effects. Previous examples of this behavior trend with coordination number,

17 while uranium oxides vary along this line according to oxidation state. This study has shown that

18 while peak fitting of the satellite features remains the most promising XPS tool for the

19 identification of valence state in oxides, analysis of the Auger parameter can yield additional

20 information on a wide variety of uranium compounds. The Auger parameter and Wagner plot

21 concepts have provided insight into initial and final state effects, as well as shielding mode,

22 relaxation energies, bonding character, and local electron densities. 
2 The authors thank Dr. Jonathan S. Morrell, Dr. Roland Schulze, Dr. Jason R. Jeffries, and Dr.

3 Nicholas P. Butch for providing samples. This work performed under the auspices of the U.S.

4 Department of Energy by Lawrence Livermore National Laboratory under contract DE-AC52-

$5 \quad 07 N A 27344$. 
$2 \quad$ 1. H. Idriss, Surf. Sci. 65, 67 (2010).

3 2. M. Schindler, F.C. Hawthorne, M.S. Freund, P.C. Burns, Geochim. et Cosmochim. Acta

$4 \quad 73,2471(2009)$.

5 3. E.S. Ilton, A. Haiduc, C.O. Moses, S.M. Heald, D. Elbert, D.R. Veblen, Geochim. et

$6 \quad$ Cosmochim. Acta 68, 2417 (2004).

$7 \quad$ 4. E.S. Ilton, J.-F. Boily, P.S. Bagus, Surf. Sci. 601, 908 (2007).

8 5. J.-F. Boily, E.S. Ilton, Surf. Sci. 602, 3637 (2008).

9 6. I. Grenthe, J. Drożdżyński, T. Fujino, E.C. Buck, T.E. Albrecht-Schmitt, and S.F. Wolf in

12 7. G. Moretti, J. Electron Spectrosc. Relat. Phenom. 95, 95 (1998).

13 8. C.D. Wagner, A. Joshi, J. Electon. Spectrosc. Relat. Phenom. 47, 283 (1988).

$149 . \quad$ C.D. Wagner, A. Joshi, Int. Anal. 6, 215 (1984).

15 10. C.D. Wagner, W.M. Riggs, L.E. Davis, J.F. Moulder, and G.E. Muilenberg (editor), 16 Handbook of X-ray Photoelectron Spectroscopy (Perkin-Elmer, Eden Prairie MN, 1979).

17 11. L.E. Davis, N.C. MacDonald, P.W. Palmberg, G.E. Riach, and R.E. Weber, Handbook of 18 Auger Electron Spectroscopy (Perkin-Elmer, Eden Prairie MN, 1978).

19 12. R. Arkush, M.H. Mintz, and N. Shamir, J. Nucl. Mater. 281, 182 (2000).

20 13. R. Arkush, M. Brill, S. Zalkind, M.H. Mintz, and N. Shamir, J. Alloys Comp. 330-332, 21

22 14. A.J. Nelson, T.E. Felter, K.J. Wu, C. Evans, J.L. Ferreira, W.J. Siekhaus, and W. 23 McLean, Surf. Sci. 600, 1319 (2006). 
1 15. R.J. McEachern and P. Taylor, J. Nucl. Mater. 254, 87 (1998).

2 16. A. Poulesquen, L. Desgranges, and C. Ferry, J. Nucl. Mater. 362, 402 (2007).

3 17. K.O. Kvashnina, S.M. Butorin, P. Martin, and P. Glatzel, Nature Chem. Submitted.

4 18. W. Siekhaus and J. Crowhurst, Mater. Sci. Eng. 9, 012055 (2010).

5 19. S.-W. Yu, J.G. Tobin, J.C. Crowhurst, S. Sharma, J.K. Dewhurst, P. Olalde-Velasco,

$6 \quad$ W.L. Yang, and W.J. Siekhaus, Phys. Rev. B 83, 165102 (2011).

7 20. S.-W. Yu, J.G. Tobin, P. Olalde-Velasco, W.L. Yang, and W.J. Siekhaus, J. Vac. Sci.

$8 \quad$ Technol. A 30, 011402 (2012).

9 21. J. S. Morrell, Y-12 Plant, Oak Ridge Tennessee.

10 22. T.T.M. Palstra, A.A. Menovsky, J. van den Berg, A.J. Dirkmaat, P.H. Kes, G.J.

11 Nieuwenhuys, J.A., Mydosh, Phys. Rev. Lett. 55, 2727 (1985).

12 23. M.B. Maple, J.W. Chen, Y. Dalichaouch, T. Kohara, C. Rossel, M.S. Torikachvili,

13 M.W. McElfresh, J.D. Thompson, Phys. Rev. Lett. 56, 185 (1986).

14 24. C. Pfleiderer, J.A. Mydosh, M. Vojta, Phys. Rev. B 74, 104412 (2006).

15 25. J.R. Jeffries, K.T. Moore, N.P. Butch, M.B. Maple, Phys. Rev. B 82, 033103 (2010).

16 26. J.R. Jeffries, N.P. Butch, B.T. Yukich, M.B. Maple, Phys. Rev. Lett. 99, 217207 (2007).

17 27. M. O'Keeffe, J. Solid State Chem. 85, 108 (1990). 
2 Table 1 Photoemission binding energy for the $U 4 f_{7 / 2}$ and $4 d_{5 / 2}$ states and $X$-ray excited Auger

3 electron kinetic energy for the $\mathrm{U} \mathrm{N}_{67} \mathrm{O}_{45} \mathrm{~V}$ and $\mathrm{N}_{6} \mathrm{O}_{45} \mathrm{O}_{45}$ transitions. All units in $\mathrm{eV}$.

\begin{tabular}{ccccc}
\hline Compound & $4 f(7 / 2)$ & $4 d(5 / 2)$ & NOO & NOV \\
\hline $\mathrm{U}$ & 377.1 & 736.0 & 187.0 & 281.0 \\
$\mathrm{U}\left(\mathrm{C}^{+}\right)$ & 377.1 & 736.0 & 186.9 & 280.9 \\
$\mathrm{URu}_{2} \mathrm{Si}_{2}$ & 378.2 & 736.6 & 185.9 & 280.7 \\
$\mathrm{UO}_{2}$ & 380.0 & 738.3 & 184.3 & 280.0 \\
$\mathrm{UO}_{2.25 / 2.33}$ & 380.1 & 738.5 & 183.8 & 279.6 \\
$\mathrm{UO}_{2.67}$ & 380.4 & 738.7 & 183.6 & 279.2 \\
$\mathrm{UO}_{3}$ & 380.8 & & 183.4 & 278.4 \\
$\mathrm{UF}_{4}$ & 382.6 & 740.9 & 179.6 & 274.8
\end{tabular}

\section{FIGURE CAPTIONS}

6 Figure $1 \mathrm{X}$-ray photoemission spectra of the $U 4 \mathrm{f}_{7 / 2}$ and $4 \mathrm{f}_{5 / 2}$ electronic states in uranium compounds

7 with a pure valence state.

8 Figure 2 Valence band region in the XPS spectrum of uranium compounds with a pure valence state.

9 Peaks are labeled with the dominant character of the emitting orbital for $\mathrm{UO}_{2}$ and $\mathrm{UF}_{4}$ as examples.

10 These same peaks are seen in $\mathrm{U}$ metal, $\mathrm{URu}_{2} \mathrm{Si}_{2}$, and $\mathrm{UO}_{3}$, but are not labeled to reduce the clutter of the 11 figure.

12 Figure 3 Auger region of the XPS spectrum of uranium metal with first derivative determined by

13 MultiPak software.

14 Figure 4 Wagner plot of the $\mathrm{U} 4 \mathrm{f}_{7 / 2}$ photoemission binding energy and $\mathrm{U} \mathrm{N}_{6} \mathrm{O}_{45} \mathrm{O}_{45} \mathrm{X}$-ray excited Auger 15 electron kinetic energy for a range of uranium compounds.

16 Figure 5 Wagner plot of the $U 4 f_{7 / 2}$ photoemission binding energy and $\mathrm{U} \mathrm{N}_{67} \mathrm{O}_{45} \mathrm{~V} \mathrm{X}$-ray excited Auger 17 electron kinetic energy for a range of uranium compounds.

18 Figure 6 Wagner plot of the $\mathrm{U} 4 \mathrm{~d}_{5 / 2}$ photoemission binding energy and $\mathrm{U} \mathrm{N}_{67} \mathrm{O}_{45} \mathrm{~V} \mathrm{X}$-ray excited Auger 19 electron kinetic energy for a range of uranium compounds.

20 Figure 7 Plot of the relationship between the Auger parameter that is determined using the $U 4 d_{5 / 2} v s$. 21 the $U 4 f_{7 / 2}$ binding energy. Both are combined with the $\mathrm{N}_{67} \mathrm{O}_{45} \mathrm{~V}$ X-ray excited Auger electron kinetic 22 energy of $U$. The slope of the line is 1 with $R^{2}=0.9$. 

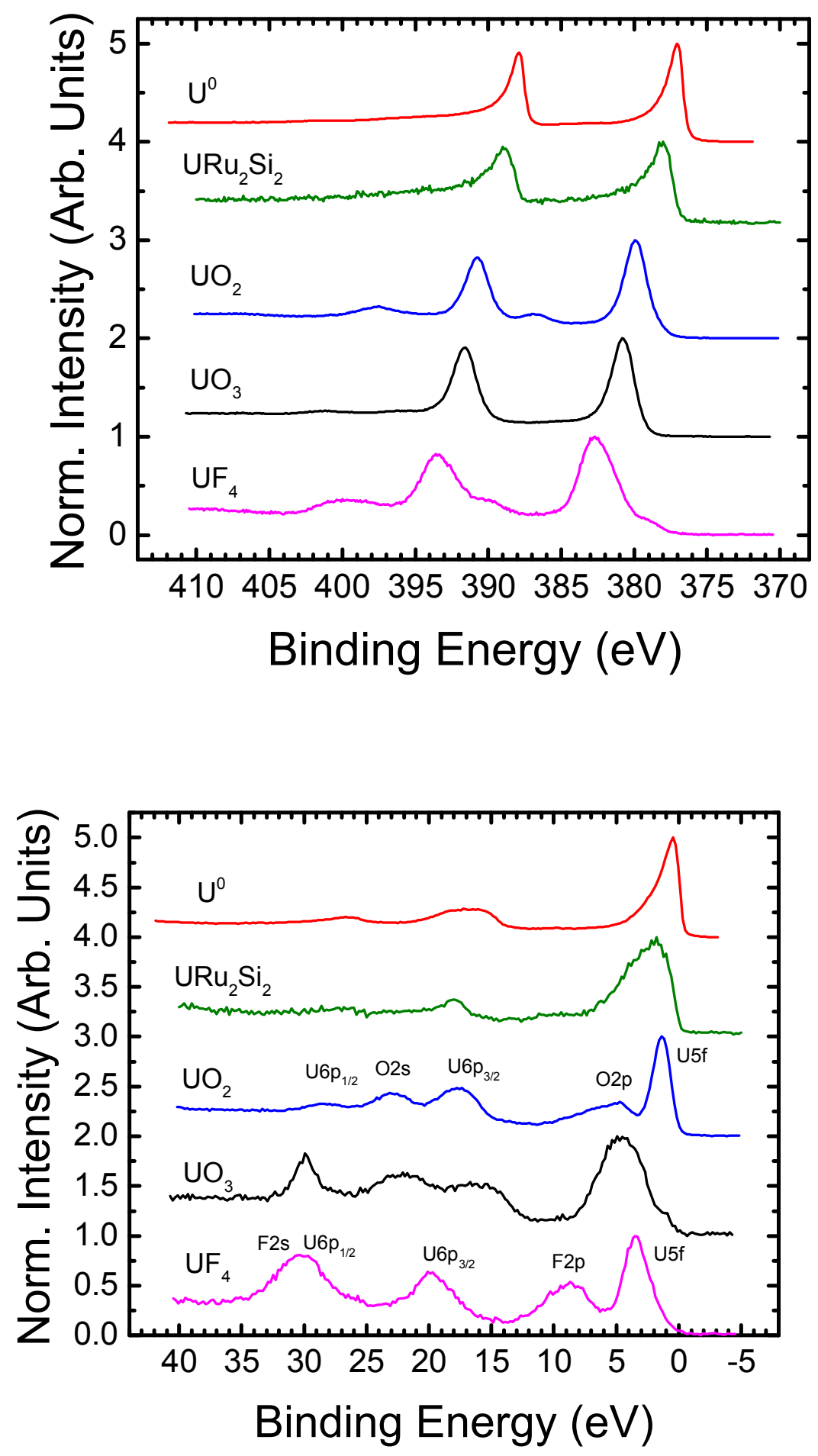

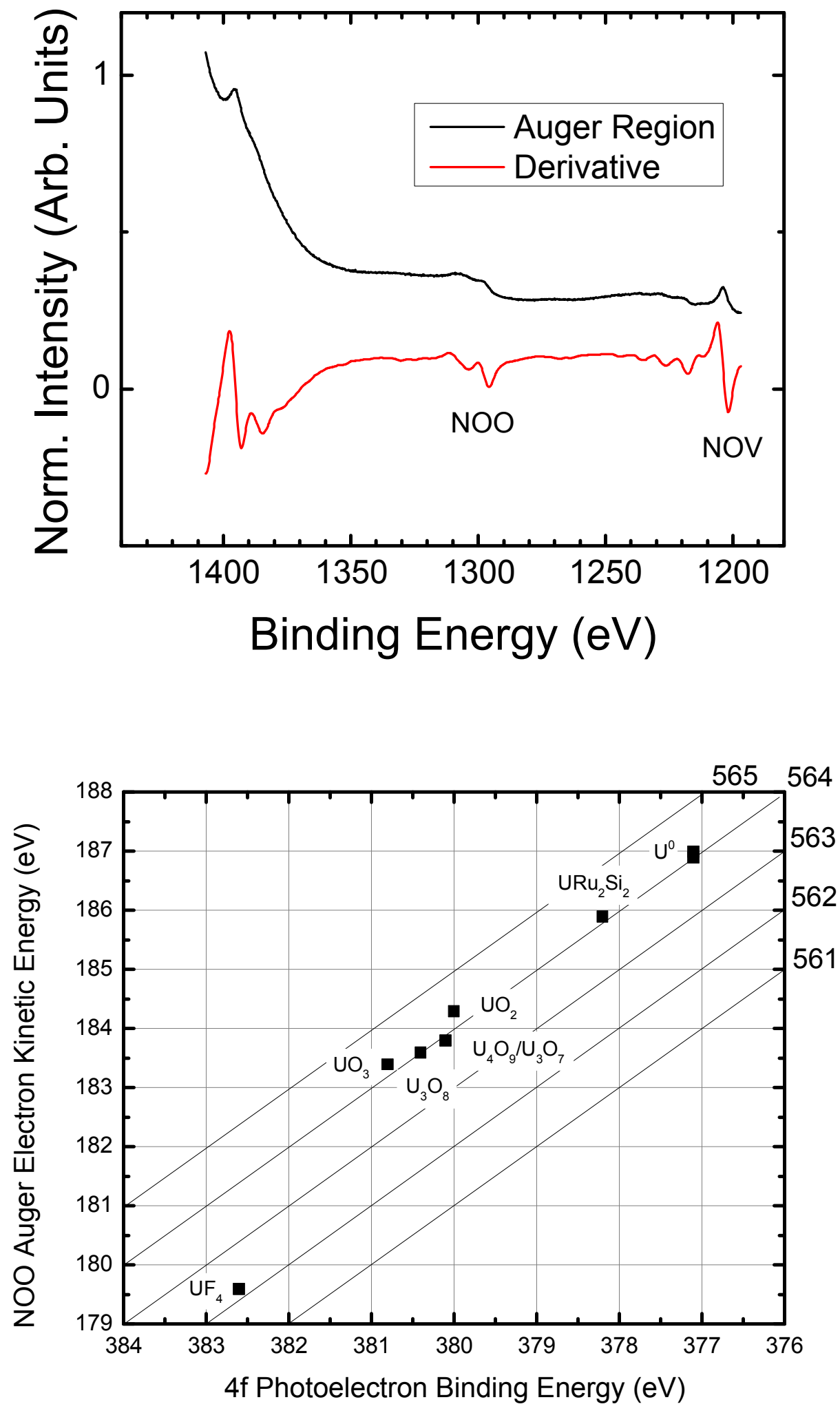


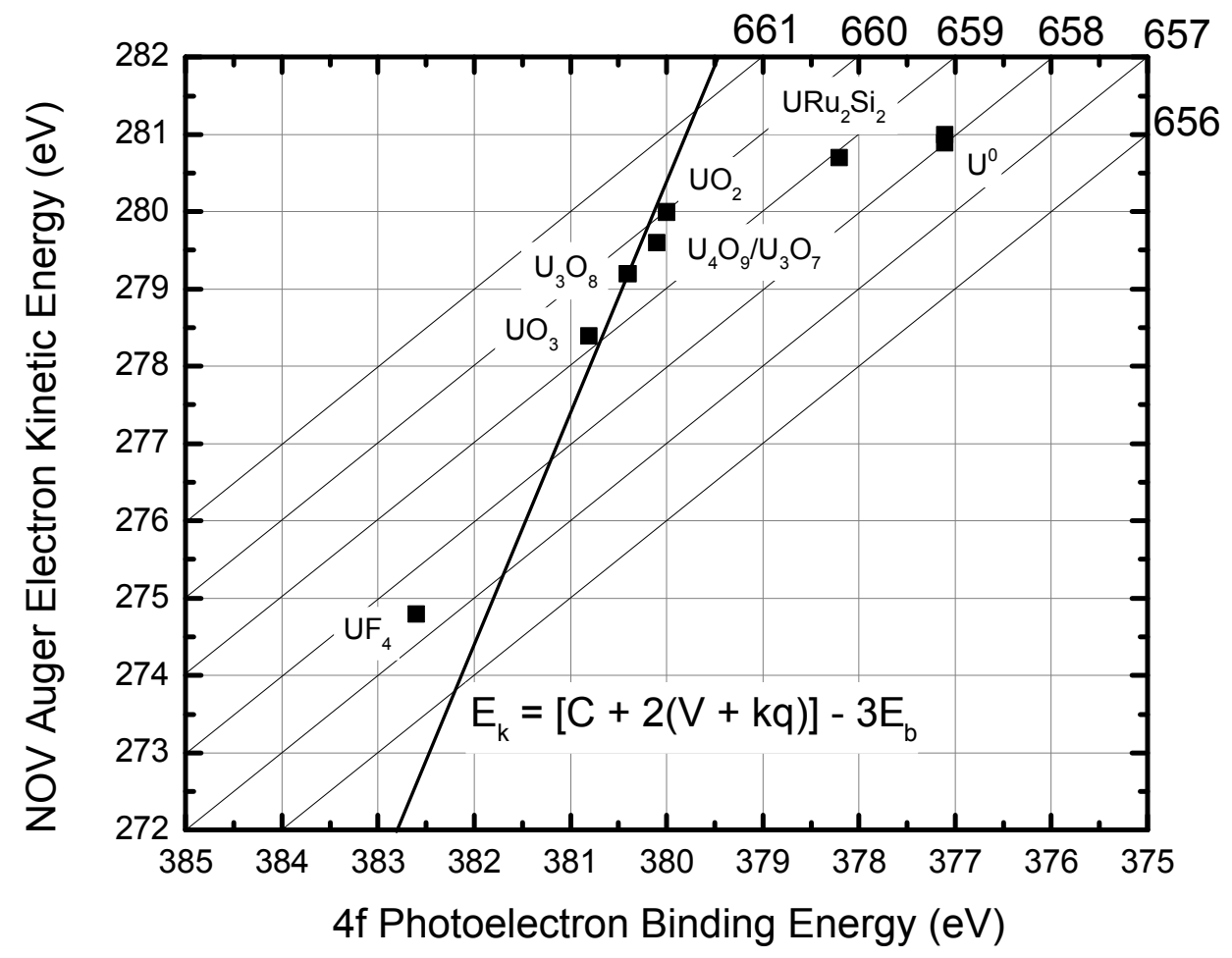

$15)$

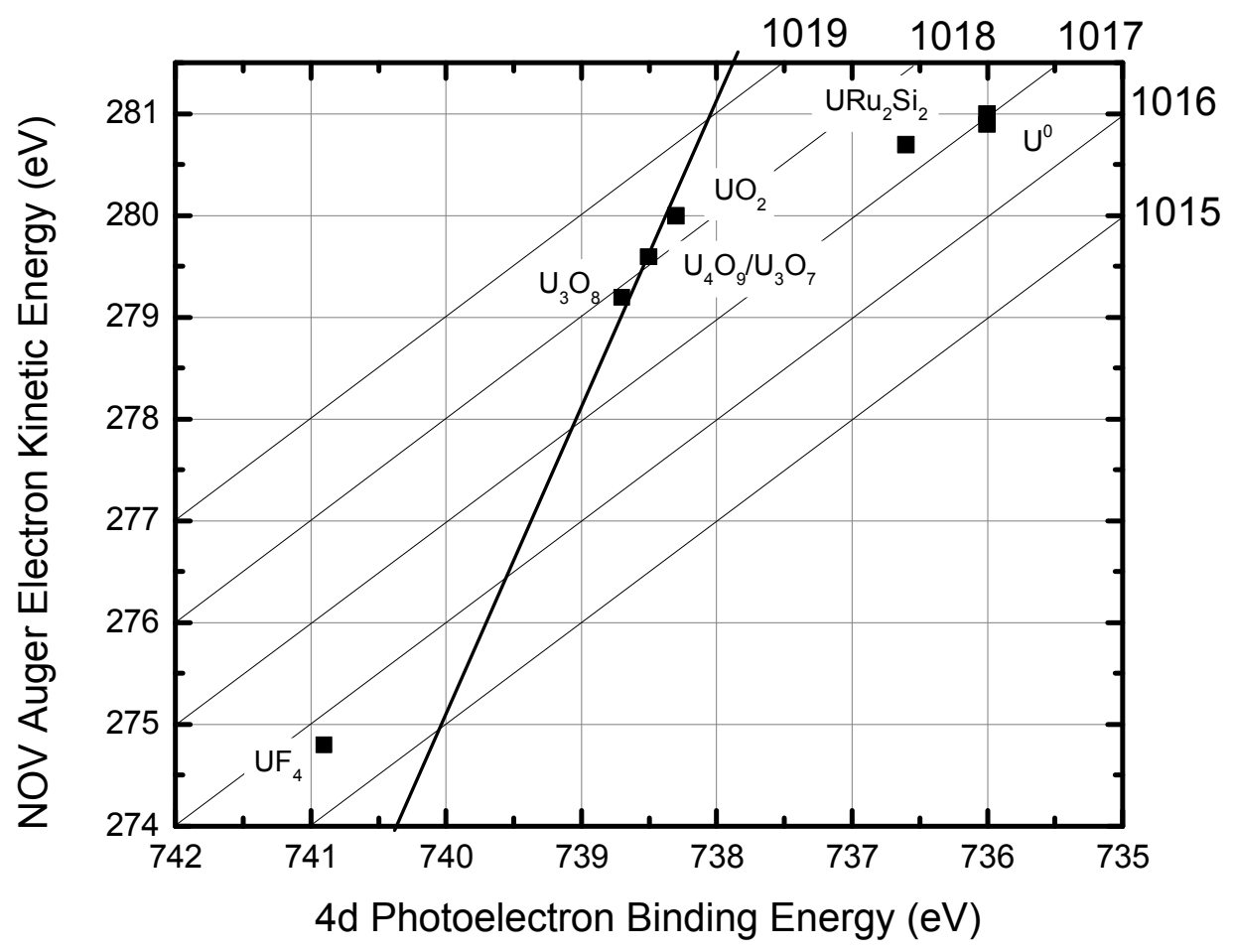

$26)$ 


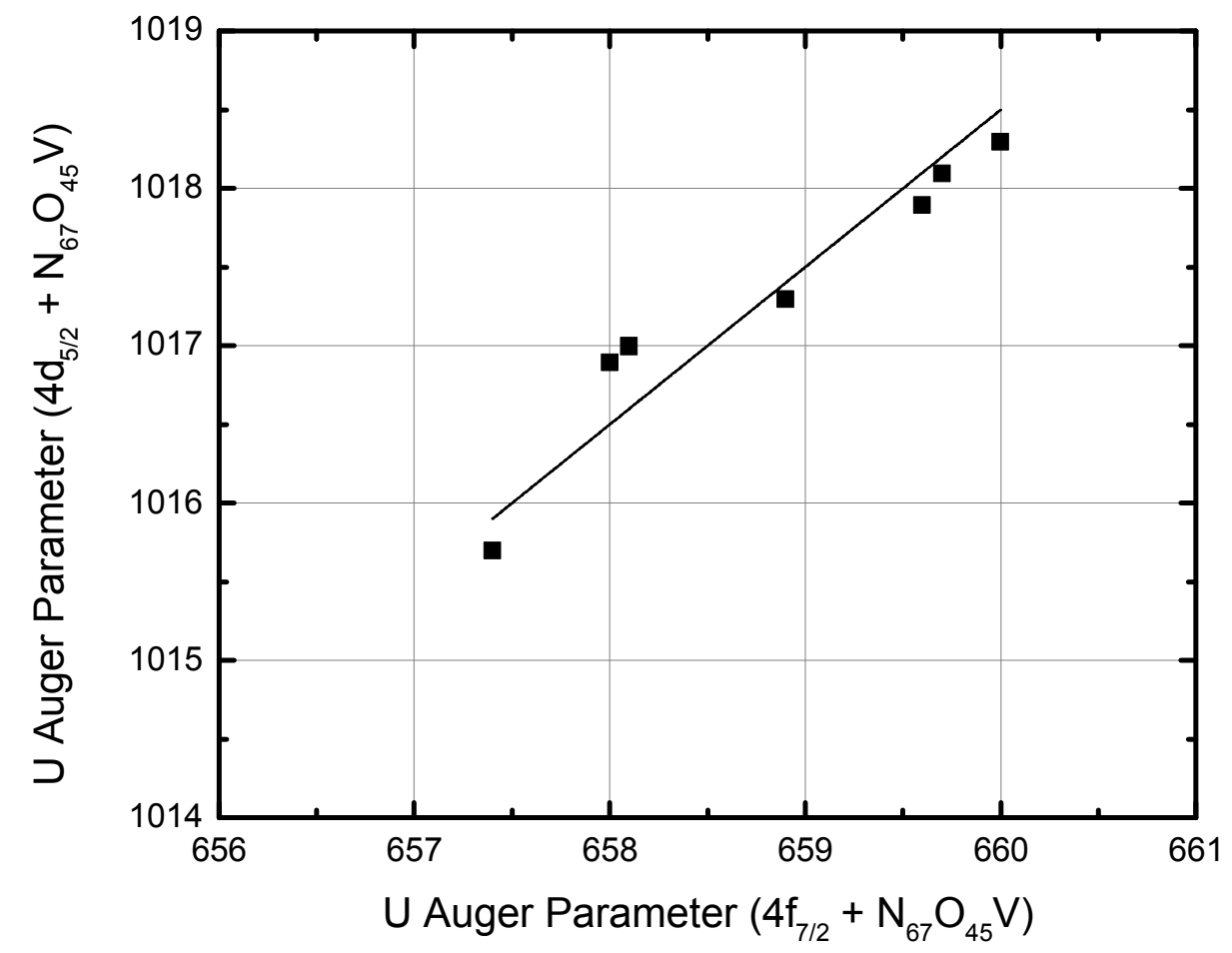

$17)$ 